\title{
Season-Long Dynamics of Spinach Downy Mildew Determined by Spore Trapping and Disease Incidence
}

\author{
R. A. Choudhury, S. T. Koike, A. D. Fox, A. Anchieta, K. V. Subbarao, S. J. Klosterman, and N. McRoberts
}

First, fifth and seventh authors: Department of Plant Pathology, University of California, Davis 95616; second author: University of California Cooperative Extension, 1432 Abbott St., Salinas 93901; third author: Fox Weather, LLC, Fortuna, CA 95540; and fourth and sixth authors: United States Department of Agriculture-Agricultural Research Service, 1636 E Alisal St., Salinas, CA 93905.

Accepted for publication 12 July 2016.

\begin{abstract}
Choudhury, R. A., Koike, S. T., Fox, A. D., Anchieta, A., Subbarao, K. V., Klosterman, S. J., and McRoberts, N. 2016. Season-long dynamics of spinach downy mildew determined by spore trapping and disease incidence. Phytopathology 106:1311-1318.

Peronospora effusa is an obligate oomycete that causes downy mildew of spinach. Downy mildew threatens sustainable production of fresh market organic spinach in California, and routine fungicide sprays are often necessary for conventional production. In this study, airborne $P$. effusa spores were collected using rotating arm impaction spore trap samplers at four sites in the Salinas Valley between late January and early June in 2013 and 2014. Levels of $P$. effusa DNA were determined by a species-specific quantitative polymerase chain reaction assay. Peronospora effusa was detected prior to and during the growing season in both years. Nonlinear time series analyses on the data suggested that the within-season dynamics

of $P$. effusa airborne inoculum are characterized by a mixture of chaotic, deterministic, and stochastic features, with successive data points somewhat predictable from the previous values in the series. Analyses of concentrations of airborne $P$. effusa suggest both an exponential increase in concentration over the course of the season and oscillations around the increasing average value that had season-specific periodicity around 30, 45, and 75 days, values that are close to whole multiples of the combined pathogen latent and infectious periods. Each unit increase in temperature was correlated with 1.7 to $6 \%$ increased odds of an increase in DNA copy numbers, while each unit decrease in wind speed was correlated with 4 to $12.7 \%$ increased odds of an increase in DNA copy numbers. Disease incidence was correlated with airborne $P$. effusa levels and weather variables, and a receiver operating characteristic curve analysis suggested that $P$. effusa DNA copy numbers determined from the spore traps nine days prior to disease rating could predict disease incidence.
\end{abstract}

The shift toward prewashed, bagged spinach has increased the demand for fresh market spinach production in the United States. Over $85 \%$ of the total United States spinach production occurs in California and Arizona (United States Department of Agriculture National Agricultural Statistics Service). The most serious threat to spinach production is downy mildew, caused by the obligate biotrophic pathogen Peronospora effusa (Grev.) Rabenh (formerly P. farinosa f. sp. spinaciae) (Choi et al. 2007). Severe downy mildew can result in postharvest rotting of spinach in salad bags or packages, leading to reduced quality and shelf life of bagged products (McKay et al. 1992). Additionally, severe spinach downy mildew may cause consumers to be wary of visibly blemished products because of previous food poisoning outbreaks and the potential for harboring foodborne pathogens in leaf lesions (Arnade et al. 2009; Simko et al. 2015). Consequently, packing companies routinely reject spinach lots at low levels of downy mildew, with anecdotal reports of disease incidence thresholds as low as one percent.

Approximately $40 \%$ of the annual United States fresh market spinach crop is produced in the Salinas Valley in California, a highly

Corresponding authors: S. J. Klosterman; E-mail address: steve.klosterman@ars.usda.gov and N. McRoberts; E-mail address: nmcroberts@ucdavis.edu

Mention of trade names or commercial products is solely for the purpose of providing specific information and does not imply recommendation or endorsement by the U.S. Department of Agriculture. USDA is an equal opportunity provider and employer.

*The $\boldsymbol{e}$-Xtra logo stands for "electronic extra" and indicates that two supplementary figures are published online.

\footnotetext{
http://dx.doi.org/10.1094/PHYTO-12-15-0333-R
}

This article is in the public domain and not copyrightable. It may be freely reprinted with customary crediting of the source. The American Phytopathological Society, 2016. productive agricultural region responsible for supplying a large proportion of many other leafy green vegetables in the United States (United States Department of Agriculture National Agricultural Statistics Service). Spinach is typically grown in the Salinas Valley between February and November, with small amounts of freezer spinach being grown during the winter (Koike et al. 2011). The valley is approximately $150 \mathrm{~km}$ long and $40 \mathrm{~km}$ wide and experiences strong diurnal fluctuations in temperature, relative humidity, and wind caused by a subsidence inversion, more commonly referred to as a marine layer. These conditions typically cause a favorable environment for fog and low clouds to develop, with accompanying leaf wetness. At times, the inversion effect can be sufficiently strong that it resists thinning and breakup of low clouds. The resulting high relative humidity and lack of surface heating help to maintain leaf wetness well beyond the typical burn-off time of midmorning (approximately 10 a.m.). The marine layer is a persistent regime during the spring to early fall months in the Salinas Valley and causes the valley to remain much cooler than surrounding foothills that are above the marine inversion, even during middays and afternoons in the early summer.

Spinach growers rely heavily on host resistance and fungicides to manage downy mildew. This reliance on resistance was relatively effective until recently, when virulent forms of $P$. effusa began to emerge in rapid succession (Correll et al. 2011; Irish et al. 2007). Organic spinach producers are especially vulnerable to these virulent strains because synthetic fungicide use is prohibited and cultivar choice is determined at planting. This has led to significant yield losses in organic spinach production.

Conventional and organic spinach growers could potentially benefit from advanced warning about disease pressure to plan an optimal spray regimen and planting dates, respectively. Many effective epidemiological models have been developed to predict plant diseases 
based on environmental conditions that are conducive to growth and reproduction of the pathogen (Dewdney et al. 2007; Gent et al. 2013; Gilles et al. 2004; Peduto et al. 2013). One potential source of error in weather-based models is the implicit assumption of the presence of pathogen inoculum (Carisse et al. 2008). While inoculum is often present in many systems, uncertainty about the presence or absence of pathogen inoculum in specific locations and times can lead to overapplication of pesticides in the absence of the pathogen. Monitoring for the presence of airborne spores or other pathogen inoculum can help increase the accuracy of disease forecasting models (Carisse et al. 2008). Many downy mildew pathogens spread rapidly through the production of wind-blown asexual sporangia. While most of the asexual spores remain local to the epidemic, some of these spores can travel long distances and can initiate epidemics in other regions or countries (Fontaine et al. 2013; LaMondia and Aylor 2001; Ojiambo and Holmes 2011; Schmale and Ross 2015; Wu et al. 2001).

Recently, several studies have combined the use of sporetrapping devices and disease forecasting models for devising regional integrated pest management programs. The integration of these tools with other disease risk indicators often increases the accuracy of the disease forecasting models by assessing the local presence of the pathogen rather than assuming presence. Detection methods have significantly advanced in recent years, from passive grease-covered glass slides to solar-powered impaction spore trap samplers linked with quantitative polymerase chain reaction (qPCR) methods, enabling detection of very low numbers of spores (Carisse et al. 2008, 2009; Klosterman et al. 2014; Thiessen et al. 2016). These advances have made it possible to accurately predict disease pressure in some cases, leading to more effective and efficient disease control measures (Carisse et al. 2011). Use of spore trapping technologies can help properly time control strategies and increase basic understanding of pathogen biology and epidemiology (Úrbez-Torres et al. 2010).

One reason for the recent shift toward species-specific qPCR detection is the co-occurrence of several species with morphologically similar structures (Falacy et al. 2007; Klosterman et al. 2014). Recent studies have shown that the organisms that cause downy mildew on plants in family Amaranthaceae are phylogenetically distinct from one another and often are associated with specific hosts (Choi et al. 2015). While there are some morphologically distinct traits that can distinguish between these species (Choi et al. 2007), many related organisms have nondescript morphologies, making accurate microscopic identification difficult. Klosterman et al. (2014) developed $P$. effusa-specific primers that can distinguish between the downy mildew pathogen on spinach and the closely related $P$. schachtii, which infects beet and Swiss chard. During the development of this assay, DNA of the spinach downy mildew pathogen was consistently detected throughout the Salinas Valley, even in warm and dry southern portions of the valley. This result was surprising, given that downy mildew diseases typically develop in cool, moist environments.

This study had the following objectives: i) to characterize the temporal pattern of airborne inoculum of P. effusa in the Salinas Valley during the critical period of the growing season from February through June; ii) to examine the degree of association between weather variables and the observed pattern of airborne inoculum; and iii) to examine the strength of association between measured airborne inoculum concentration and observed disease incidence in spinach crops.

\section{MATERIALS AND METHODS}

Spore trapping and Peronospora effusa-specific qPCR. The rotating arm impaction spore trap samplers used in this study were obtained from W. Mahaffee (United States Department of Agriculture-Agricultural Research Service [USDA ARS], Corvallis, OR). The traps were deployed as previously described (Klosterman et al. 2014), with the exception that they were placed in pairs, at a spacing of 1 to $2 \mathrm{~m}$ between traps at four sites in the Salinas Valley (Supplementary Fig. S1). The sites were selected for their proximity to spinach production areas. The traps were deployed in late January in both 2013 and 2014, prior to the start of spring spinach plantings in early March. Spore trap samplers operated continuously throughout the study period, and the 40-mm stainless steel, grease-coated spore trap rods (316LSi stainless steel; Harris Products Group, Mason, $\mathrm{OH}$ ) were collected three times a week at 48-, 48-, and 72-h intervals from late January to early June in both years and were stored at $4^{\circ} \mathrm{C}$ until processing. The rods were processed within two weeks of collection, and remaining samples were stored at $-80^{\circ} \mathrm{C}$.

DNA extractions from the impaction spore trap sampler rods (NucleoSpin Plant II kit; Machery-Nagel) and qPCR (TaqMan) assays with the single nucleotide polymorphism-specific primers for each species, $P$. effusa and $P$. schachtii, were carried out and results were expressed as copy number of $P$. effusa ribosomal DNA, as previously described (Klosterman et al. 2014).

Disease incidence rating. Commercial spinach fields located near traps were rated for disease incidence weekly, using a cluster sampling method. Fields were divided into $70 \times 70-\mathrm{m}$ sections and were rated using a notional ' $\mathrm{X}$ ' pattern to separate individual sampling points, which were located at the arm-ends of the ' $\mathrm{X}$ '. Four adjacent $1-\mathrm{m}^{2}$ quadrats of spinach were rated at each sampling point for disease incidence (presence or absence on individual leaves) of downy mildew symptoms by estimating the proportion of infected leaves in each quadrat. Samples of diseased leaves were collected from affected fields and DNA from $P$. effus $a$ and the qPCR assay was used to cross-validate the visual symptoms. The study period (February through June) was longer than the crop life of spinach, which is typically harvested within 30 to 45 days. As such, several different fields surrounding each trap were rated over the course of each season.

Weather data. High-quality weather data for individual sites were generated by Fox Weather, LLC (www.foxweather2.com), using the MtnRT custom software described in a summary by A. D. Fox. Hourly interpolation of meteorological variables, including temperature, relative humidity, wind speed, and wind direction on a $1.5-\mathrm{km}$ grid was done by MtnRT for both seasons, with supplemental data from the virtual weather stations as available (Coop et al. 2009).

Nonlinear time series analysis. The overall dynamical properties of the spore trap data series from each site-year were assessed using NLTSM software (nonlinear time-series modeling) (Turchin 2003). NLTSM helps to characterize nonlinear data to assess if systems are characterized by stochastic or chaotic effects and if there is shortterm predictivity in the system. In particular, the coefficient of prediction and Lyapunov exponent values were used to indicate the balance between stochastic noise and chaos in the series (Turchin 2003).

Trend and periodicity. Linear regression of the natural log of the spore trap copy numbers against time was used to extract the trend from each series. The resulting residuals were fitted to a periodvariable periodic wave function of form,

$$
y=\sin ((2 \pi / \theta) t)
$$

where $\theta$ is the period, $y$ are the residuals of the linear regression, and $t$ is the time. The value of $\theta$ was increased in 1-unit increments from 1 to 1 less than the length of each series and the coefficient of determination $\left(R^{2}\right)$ was recorded. The periodic function with the highest $R^{2}$ value was fitted to the data, and the fitted values were subtracted from the data to recover a second set of residuals, which, in turn, were assessed for evidence of periodicity. This iterative process of recovering statistically significant periods was repeated until the residuals contained no detectable periodicity. A statistical process model for each year's data were constructed by combining the estimated linear trend for the mean trap DNA copy number with 
the significant periods identified for that season. The fitted process model had the form

$$
y(t)=a+b t+\sum_{n} \sin \left(\frac{2 \pi}{\theta_{n}}\right)(t)
$$

where $y(t)$ is the estimated logarithm of the trap DNA copy number at time $t, a$ is the intercept of the linear regression, $b$ is the slope yearspecific linear rate of increase with time, and $\theta_{n}$ are the $n$ period values detected in each year's data.

The use of a periodic function allows for specification of the time interval, which offers an advantage over Fourier-type analyses that have as a base-assumption that the data were collected on a regular interval. While most Fourier-type analyses are fairly robust against slight alterations to a regular series, the regularity of the irregular sampling period (48, 48, and $72 \mathrm{~h}$ ) would create artifacts in our data, skewing our analysis.

Receiver operating characteristic curve. The spore trap data were assessed for their predictive capacity for future disease incidence of nearby crops. A case/control approach was used (Carisse et al. 2008; Yuen and Hughes 2002). Cases were defined as location-times at which average site disease incidence rating was greater than or equal to $0.1 \%$, and controls were defined as crops with less than $0.1 \%$ incidence by site. Spore trap data at successive lag times before each disease observation were translated into an ordinal categorical scale using $e^{x}$ as the scale values, where $x$ is a member of the set of values $0,0.5,1,1.5 \ldots 13$. Each trap observation was allocated to the closest scale value. The predictive capacity of the traps was assessed by taking each scale value in turn and assigning predictions of future disease status as either at-or-above or below the disease incidence threshold of $0.1 \%$, depending on the spore trap index value. The predicted status of disease at each location-time as a case or control could then be compared with its actual case/control status obtained from the disease sampling exercise; the sampling data acted as the gold standard for comparison. Overall accuracy of the trap data at different combinations of time lag and scale values was assessed by calculating Youden's Index (= true positive proportion + true negative proportion -1 ) and the positive and negative likelihood ratios for cases for each lag and scale value combination (Hughes and McRoberts 2014). The positive likelihood ratio for cases is the weight of evidence contained in a trap reading that a future observation of disease will be above the threshold, while the negative likelihood ratio measures the weight of evidence against a future observation of disease being above the threshold (Carisse et al. 2008; Hughes and McRoberts 2014; Yuen and Hughes 2002). The combined data set for 2013 and 2014 consisted of 87 crop location-times, composed of 46 gold-standard cases and 41 goldstandard controls. The area under the receiver operating characteristic (ROC) curve was calculated using integration methods, to assess the overall quality of different predictors and to allow direct comparison of the disease predictive capacity between different time lags (Hanley and McNeil 1982).

Logistic regression of spore trap data on weather variables. Site-specific spore trap data were transformed by calculating differences between successive observations. This allowed transformation of the series of $n$ observations into series of $n-1$ binary values, in which a value of 1 corresponded to a pair of successive observations between which $P$. effusa DNA copy number increased and 0 corresponded to a period in which copy number decreased. Site-specific weather variables from the trapping periods were divided into six 4-h periods per day and logistic regression was used to examine the potential for weather data averaged within periods to predict the probability of observing increases in P. effusa DNA copy number (Wu et al. 2005). Regression coefficients were converted to odds ratios, an estimate of the change in the odds for the increase in spore copy numbers if the state of the weather variable changes by 1 .

Logistic regression of disease incidence data on spore trap data and weather variables. Site-specific weather variables from the trapping periods were divided into six 4-h periods per day and averaged over each week. Site-specific disease incidence and spore copy number data were also averaged weekly. Using the case/ control method as described in the ROC analysis, disease status was segregated as either at-or-above or below the disease incidence threshold of $0.1 \%$, depending on the spore trap index value. A stepwise logistic regression was used to assess whether the natural $\log$ of the average spore copy number and the averaged weather variables from the week prior were predictive of future disease presence for each site.

\section{RESULTS}

Peronospora effusa was detected throughout both growing seasons at all four sites (Figs. 1 and 2). On average, the detectable P. effusa levels were higher in 2013 than in 2014. Results from the NLTSM analysis suggested that most of the spore trap time series had a Lyapunov exponent that was negative or close to zero. Two of the nine site-year time series (Soledad in 2014 and King City South in 2013) had positive Lyapunov exponents. The coefficient of prediction for all site-years was consistently above zero (Fig. 3). These results are indicative of a data-generating process that has some short-term predictability but has considerable stochasticity.

The mean DNA copy number per trapping interval was 1,509 in 2013 and 796 in 2014. Across all four sites, there was an overall increase in the spore copy number in both years, as the season progressed. When transformed to a natural log scale, the increasing trend over time for spore copy number was described, using simple linear regression in both years (Fig. 2).

After removal of the increasing time trend, results from fitting a periodic function to the residuals of the linear regression suggested that there was a significant periodicity in both 2013 and 2014 (Fig. 2). In 2013, significant periodicity occurred at intervals of 26 and 44 days, while in 2014, significant periods of 30, 45, and 75 days were detected (Table 1). Combining the linear trend with periodic forcing ( $\sin$ ) functions for each year resulted in statistical process

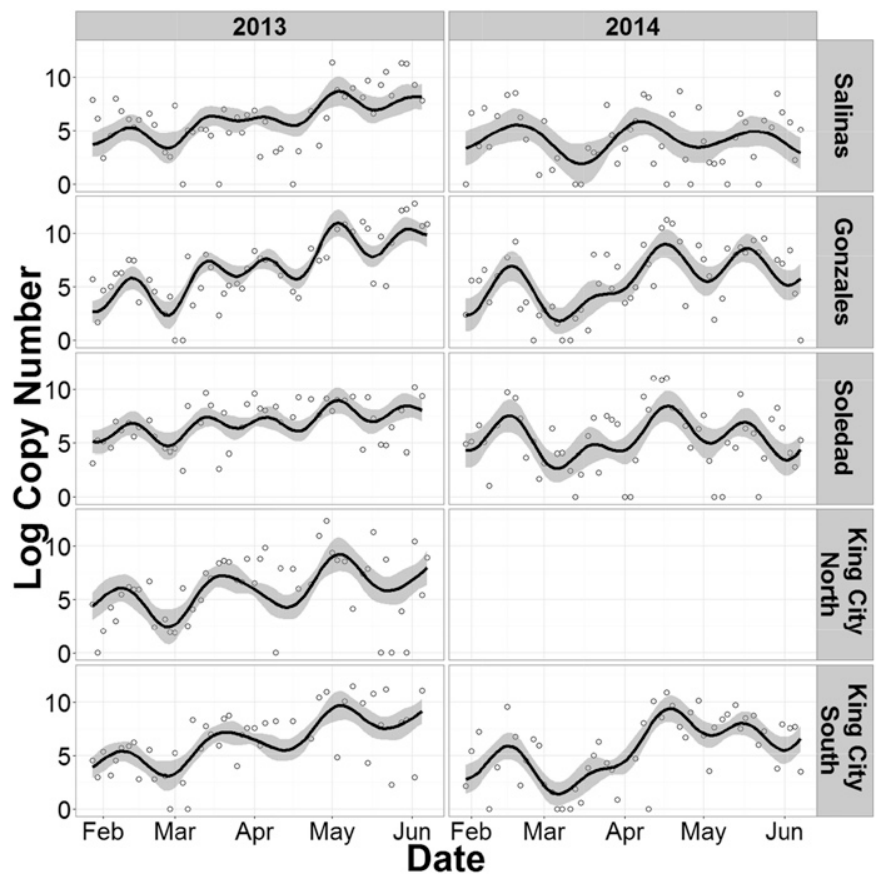

Fig. 1. The mean of the natural log-transformed ribosomal DNA copy numbers of Peronospora effusa averaged daily from the nine site-years. Solid black lines represent results from the linear and periodic regression, with gray areas representing 95\% confidence intervals. No data were collected at the King City North site in 2014. 
models that accounted for approximately $83 \%$ of the variance in trap DNA copy number in 2013 and 61\% in 2014 (Fig. 2).

Results from the ROC curve analysis suggested that spore copy number is able to predict disease incidence levels at 0,1 , and 4 lags prior to the disease incidence rating, roughly approximating lags of 0,2 , and 9 days. Observations corresponding to lag 4 gave the highest overall predictive accuracy and are the only ones among those with predictive capacity that would allow sufficient time for a response by growers. At lag 4, using a spore trap copy number of $e^{8}$ as the action threshold, Youden's Index was 0.35 . The positive likelihood ratio for disease increase was 2.36 and the negative likelihood ratio for disease increase was 0.53 . Observing $e^{8}$ trap copy numbers or more on day $t$ more than doubled the odds of observing greater than $0.1 \%$ disease at day $t+9$, while observing fewer than $e^{8}$ copies on traps on day $t$ reduced the odds of observing $0.1 \%$ or more disease on day $t+9$ by roughly half. There was little to no predictive capacity of the spore trap data at time lags 2 and 3 for subsequent disease incidence, as indicated by the proximity of the ROC curves for these lags to the line of no discrimination (Fig. 4). The area under the ROC curve (AUROC) is frequently used as a diagnostic to assess the quality of a predictive system as well as to compare between multiple predictors. An AUROC of 0.5 indicates that the predictor is not different from the line of no discrimination. The AUROC for lags 0 through 4 were $0.649,0.685,0.505,0.523$, and 0.688 , respectively.

The logistic regression analysis of the relationship between changes in airborne inoculum levels and weather variables suggested that there was a higher probability of observing an increase in trap DNA copy number when temperatures were higher than average during any of the 4-h periods examined (Table 2). In addition, decreased wind for all time periods, except between 6 to 10 a.m., was significantly correlated with higher probability of observing an increase in $P$. effusa DNA levels on traps. Increased relative humidity in the periods 10 to $2 \mathrm{p} . \mathrm{m}$. and 6 to $10 \mathrm{p} . \mathrm{m}$. had a low but significant positive correlation with increased probability of observing higher $P$. effusa levels. Similar effects were noted for the weather conditions one lagged trapping period before each observation of change in the DNA copy number.

The stepwise logistic regression analysis suggested that several site-specific weather variables and spore copy numbers were predictive for future disease incidence. In general, cool and moist nights, warm and dry mornings, and increased levels of spore copy numbers were predictive of disease presence in the upcoming week (Table 3).

Disease incidence and spore copy number levels followed in a lagged delay pattern (Fig. 5). Disease incidence levels were higher on average in 2013 compared with 2014, matching the situation for spore copy numbers. In 2013, disease incidence increased dramatically in April and peaked twice, in mid- to late April and again in mid- to late May. In 2014, the maximum levels of disease were lower than in 2013, but disease appeared earlier in the season (in mid-March) and had three peaks, mid- to late March, mid-April, and early to mid-May. Peronospora effusa DNA extracted from pathogen samples collected from infected fields was consistently

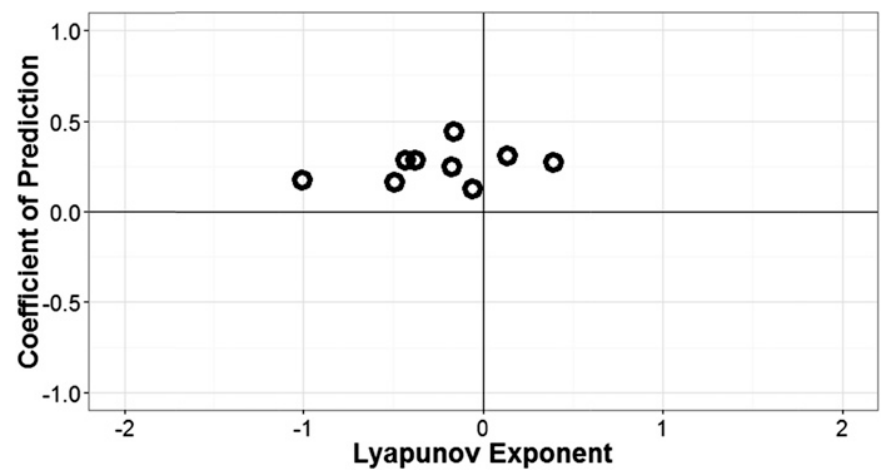

Fig. 3. Scatterplot of the Lyapunov exponent and the coefficient of prediction from each of the nine site-years.

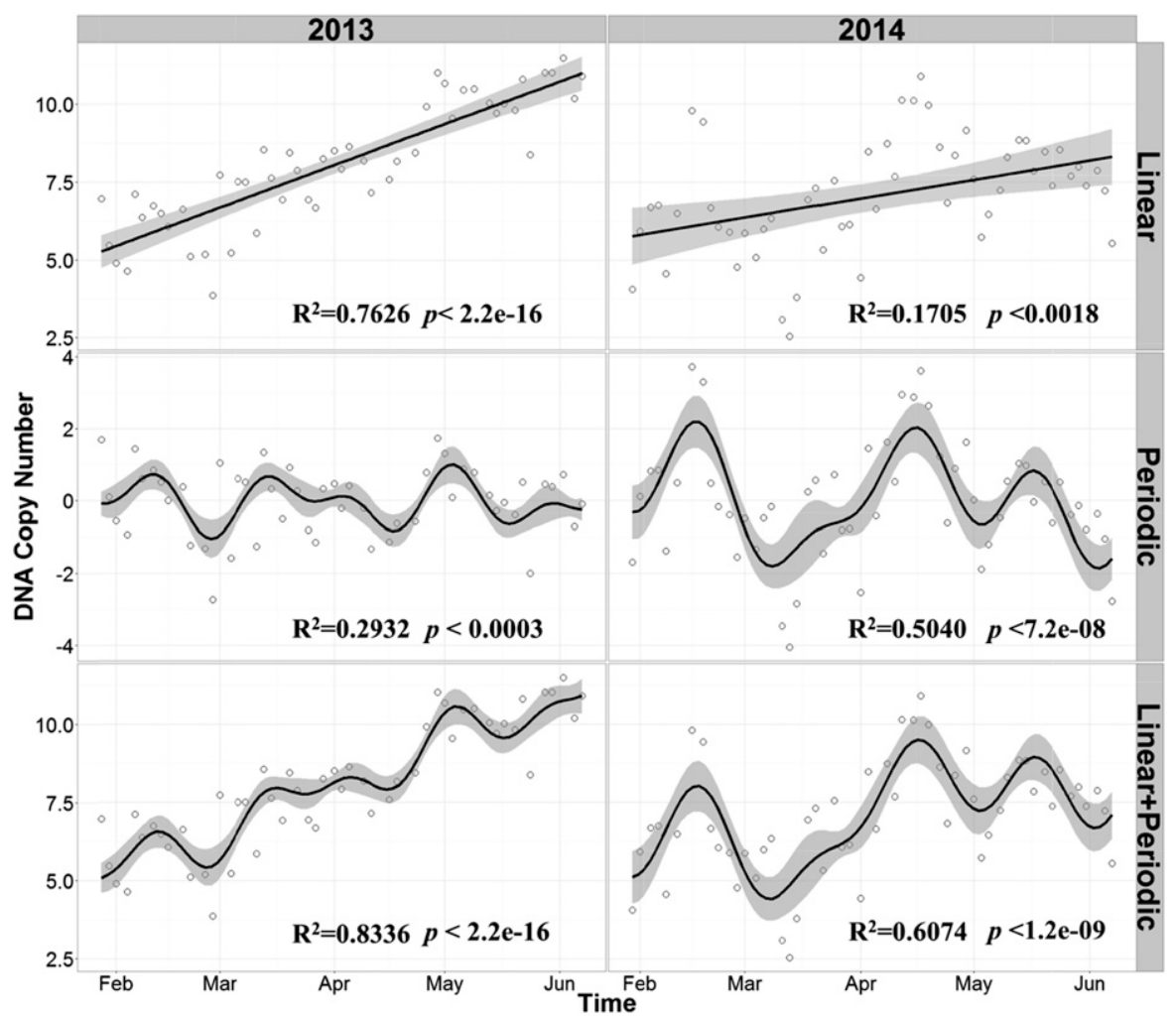

Fig. 2. The mean of the natural log-transformed ribosomal DNA copy numbers of Peronospora effusa averaged daily across all sites in 2013 and 2014 . Solid black lines represent results from regression analyses, with gray areas representing 95\% confidence intervals. The periodic and linear and periodic regressions were based on each year's period with the maximum coefficient of determination, which were 26 and 44 for 2013 and 30, 45, and 75 for 2014, respectively. 
amplified using the primers developed by Klosterman et al. (2014), suggesting that the primers are robust.

\section{DISCUSSION}

In this study, levels of $P$. effusa were monitored by impaction spore trap samplers and qPCR at four sites throughout the Salinas Valley, California, a major spinach production region in the United States. The overall objectives of this study were to determine whether the spinach downy mildew pathogen P. effusa is detectable prior to and during the spring growing season in the Salinas Valley, whether levels vary between locations, and whether pathogen DNA copy number levels are related to local disease incidence or weather variables. Understanding how airborne inoculum concentration (as estimated by trap spore copy number) varies within and between locations can help reveal basic aspects of the pathogen biology as well as enable adjustments to be made for managing the disease (Carisse et al. 2009, 2011). Understanding how local disease levels

TABLE 1. Parameter estimates for fitting linear + periodic statistical models to spore trap DNA copy number data for Peronospora effusa in two growing seasons in the Salinas Valley in California ${ }^{a}$

\begin{tabular}{llrcc}
\hline Year & \multicolumn{1}{c}{ Parameter } & $\begin{array}{c}\text { Parameter } \\
\text { estimate }\end{array}$ & $\begin{array}{c}\text { Standard } \\
\text { error estimate }\end{array}$ & $t$ value (prob) \\
\hline 2013 & Intercept & -0.072 & 0.4942 & $-14.54(<2 \mathrm{E}-16)$ \\
2013 & Time coefficient & 0.046 & 0.0031 & $14.70(<2 \mathrm{E}-16)$ \\
2013 & Periodic (26 days) & -0.447 & 0.1640 & $-2.73(<0.009)$ \\
2013 & Periodic (44 days) & -0.604 & 0.1715 & $-3.52(<0.001)$ \\
2014 & Intercept & -0.043 & 0.7359 & $-5.84(<4 \mathrm{E}-07)$ \\
2014 & Time coefficient & 0.020 & 0.0060 & $3.30(<0.002)$ \\
2014 & Periodic (30 days) & 0.767 & 0.2300 & $3.33(<0.002)$ \\
2014 & Periodic (45 days) & 0.745 & 0.2350 & $3.17(<0.003)$ \\
2014 & Periodic (75 days) & -1.290 & 0.2309 & $-5.59(<9.5 \mathrm{E}-07)$ \\
\hline
\end{tabular}

a Data were converted to natural logarithms before parameter estimation.

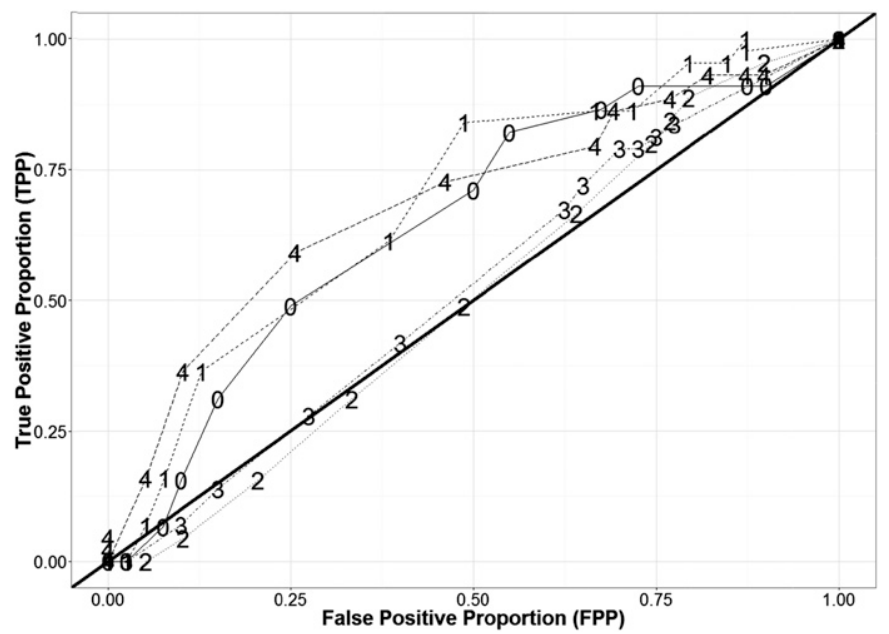

Fig. 4. Receiver operating characteristic curve for different lags. Numbers indicate the lag period of the ribosomal DNA copy number from Peronospora effusa before the downy mildew disease incidence rating. Solid diagonal line represents the line of no discrimination. and weather variables affect spore load is also a vital part of the assessment of whether the technology can be used to improve disease management by growers.

Long term dynamics of $P$. effusa levels can help describe underlying processes in the disease system. The Lyapunov exponent $(\lambda)$ provides a diagnostic for whether systems are stochastic and will converge to an equilibrium $(\lambda<0)$ or chaotic and will diverge from an equilibrium $(\lambda>0)$ (Turchin 2003). The results from the NLTSM analysis suggest that the spinach downy mildew pathosystem in the Salinas Valley lies at the border between these dynamic domains, with the balance between chaotic and stochastic properties in specific time series depending on location and year. These observations are consistent with the idea that many pathogen population dynamics are driven by both exogenous and endogenous factors that combine stochastic noise with broad deterministic rules.

In general, endogenous life history factors (such as reproduction) for microbes are strongly influenced by exogenous, stochastic variation in environmental conditions. Discrete events introduced by human actions, such as crop harvest or pesticide application, in contrast, can impose local discontinuities in population dynamics, leading to the generation of chaotic properties (Hughes and Gonzalez-Andujar 1997). Many real populations are, thus, subject to a mixture of noisegenerating and chaos-generating influences and display dynamics in the transition zone between the two domains, a phenomenon that Turchin (2003) characterized as quasi-chaotic dynamics.

While the Lyapunov exponent values suggest that the pathosystem is close to the boundary between stochastic and chaotic dynamics, the coefficient of prediction was consistently greater than zero. This suggests that the dependence of $P$. effusa airborne inoculum levels on past levels can be estimated and that such a statistical description will provide a better predictive estimate than simply using mean levels (Turchin 2003). The presence of statistically significant trends and periodic components in the data from both years supports the implications from the NLTSM analyses. These analyses are relatively novel in plant pathology, although Skelsey et al. (2009) used the coefficient of prediction by Turchin (2003) as one of several metrics to evaluate spatiotemporal models of potato late blight disease. The combination of the coefficient of prediction and Lyapunov coefficient has been used to describe dynamics in other biological systems, notably several insect pests (Turchin 2003). Hernández Plaza et al. (2012) found that the dynamics of plant populations were also influenced by both exogenous and endogenous factors. They noted that, while some of their populations seemed to be driven by endogenous factors that might be expected to generate chaos, very few field studies have been confirmed as chaotic systems.

Peronospora effusa detection increased exponentially over the course of growing seasons both in 2013 and 2014, consistent with other spore trapping studies (Byrne et al. 2000, 2005; Carisse and Philion 2002; Granke and Hausbeck 2011). In the case of an obligate biotroph such as P. effusa, it is probable that the exponential increase in airborne inoculum is driven by host availability in the Salinas Valley. Host availability dramatically increases after the initial spring planting in March each year and varies with market demand and individual crop growth duration until June, when crop production temporarily shifts to alternative growing areas.

Although $P$. effusa was detected almost continuously throughout both growing seasons, there was strong evidence for intraseason

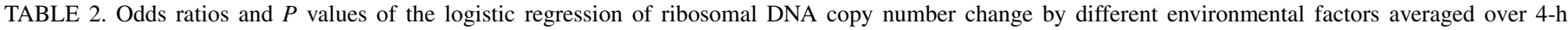
time blocks

\begin{tabular}{|c|c|c|c|c|c|c|c|}
\hline Lag & Environmental factor & 10 a.m.-2 p.m. & 2 p.m. -6 p.m. & 6 p.m. -10 p.m. & 10 p.m.-2 a.m. & 2 a.m.-6 a.m. & 6 a.m. -10 a.m. \\
\hline 0 & Air temperature $\left({ }^{\circ} \mathrm{C}\right)$ & $1.0422(<0.0001)$ & $1.0421(<0.0001)$ & $1.0595(<0.0001)$ & $1.0392(0.0002)$ & $1.0339(0.0003)$ & $1.0167(0.0430)$ \\
\hline 0 & Relative humidity (\%) & $1.009(<0.0001)$ & $1.0044(0.0625)$ & $1.0054(0.0250)$ & $1.0036(0.1778)$ & $1.0046(0.1634)$ & $1.0043(0.1083)$ \\
\hline 0 & Wind speed $(\mathrm{m} / \mathrm{s})$ & $0.9606(0.0405)$ & $0.9094(<0.0001)$ & $0.9404(0.0006)$ & $0.8733(<0.0001)$ & $0.8995(0.0012)$ & $0.9884(0.6779)$ \\
\hline 1 & Air temperature $\left({ }^{\circ} \mathrm{C}\right)$ & $1.0203(0.0201)$ & $1.0233(0.0113)$ & $1.0359(0.0007)$ & $1.0235(0.0213)$ & $1.0009(0.9183)$ & $1.0099(0.2258)$ \\
\hline 1 & Relative humidity (\%) & $1.0072(0.0016)$ & $1.0029(0.2128)$ & $1.0041(0.0846)$ & $1.005(0.0594)$ & $1.0095(0.0046)$ & $1.0072(0.0072)$ \\
\hline 1 & Wind speed $(\mathrm{m} / \mathrm{s})$ & $0.949(0.0073)$ & $0.9397(<0.0001)$ & $0.9601(0.0223)$ & $0.9425(0.0308)$ & $0.9565(0.1697)$ & $0.9606(0.1539)$ \\
\hline
\end{tabular}


periodicity. The dominant periods differed between 2013 and 2014, but stable periodicity was observed in both years at approximately 30 and 45 days. In 2014, a longer period of 75 days occurred. It is currently not clear what the source of the periodicity is. It may arise as an emergent property of the interaction between overlapping cycles of infection and factors connected with the cropping cycles. The latent period for spinach downy mildew is thought to be about 7 days and the infectious period is about 9 days (van den Bosch et al. 1988).

The observed dominant periodicities in the data correspond to approximately two, three, and five times the combined latentinfectious period for the pathogen, suggesting that peaks in spore trap detection may have followed periods when planting duration was sufficient to allow multiple rounds of the pathogen infection cycle. The multiple asynchronous infection cycles and asynchronous planting and harvesting schedules likely distort any natural periodicity in spore production arising from the intrinsic life-cycle biology of the pathogen. The observed dynamics of the time series of trap catches are consistent with this hypothesis.

Peronospora effusa was detectable at all sites more or less continuously throughout both growing seasons in 2013 and 2014. In comparable studies of other plant pathogens, detection of airborne inoculum has been found to be more sporadic (Carisse et al. 2009; Eskalen et al. 2013; Granke et al. 2009). Overlapping crops of spinach are planted in the Salinas Valley from February through November, and new production practices, such as wider planting beds, ensure dense plantings. Overhead irrigation is a routine practice, providing ample moisture for the sporulation and splash dispersal of many fungal and oomycete pathogens (Eskalen et al. 2013; Savory et al. 2011; Úrbez-Torres et al. 2010). Moreover, the northern end of the valley is regularly inundated with a marine fog layer. This regular presence of fog and the dense cropping may allow the spinach downy mildew pathogen to maintain some level of

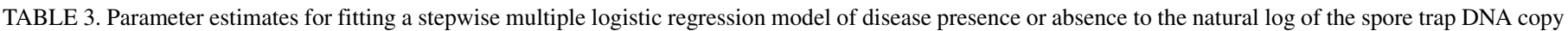
number data for Peronospora effusa and 4-h time blocks of weather variables from the week prior in two growing seasons in the Salinas Valley in California

\begin{tabular}{|c|c|c|c|c|}
\hline Parameter & Time period & Parameter estimate & Standard error estimate & $z$ value (prob) \\
\hline Intercept & NA & 7.8606 & 8.4116 & $0.934(0.3501)$ \\
\hline Relative humidity (\%) & 2 a.m.-6 a.m. & -0.3205 & 0.1375 & $-2.331(0.0198)$ \\
\hline Air temperature $\left({ }^{\circ} \mathrm{C}\right)$ & 6 a.m.-10 a.m. & 1.0130 & 0.3859 & $2.625(0.0087)$ \\
\hline Air temperature $\left({ }^{\circ} \mathrm{C}\right)$ & 10 a.m.-2 p.m. & -0.7842 & 0.2914 & $-2.691(0.0071)$ \\
\hline Air temperature $\left({ }^{\circ} \mathrm{C}\right)$ & 6 p.m. -10 p.m. & 1.1877 & 0.5102 & $2.328(0.0199)$ \\
\hline Air temperature $\left({ }^{\circ} \mathrm{C}\right)$ & 10 p.m.-2 a.m. & -1.8064 & 0.6075 & $-2.974(0.0029)$ \\
\hline Relative humidity (\%) & 10 p.m.-2 a.m. & 0.2864 & 0.1101 & $-2.974(0.0029)$ \\
\hline Natural log of spore copy number & NA & 0.3316 & 0.1276 & $2.599(0.0094)$ \\
\hline
\end{tabular}

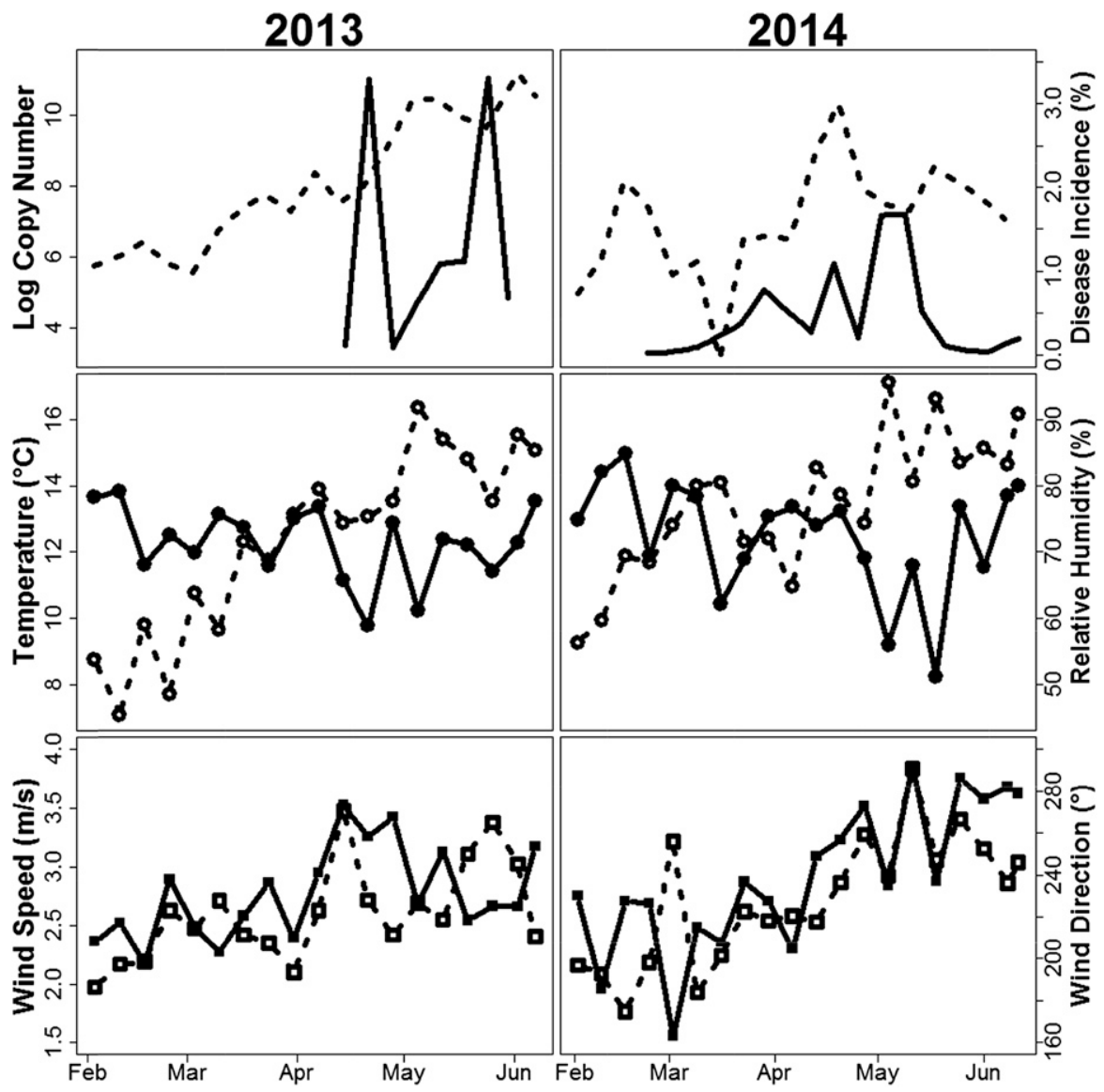

Fig. 5. Average weekly downy mildew disease and ribosomal DNA copy numbers from Peronospora effusa in 2013 and 2014. Dotted lines represent ribosomal DNA copy number and solid lines represent disease incidence ratings. Dotted lines with empty circles represent average weekly temperature and solid lines with solid circles represent relative humidity. Dotted lines with empty squares represent average weekly wind speed and solid lines with solid squares represent wind direction. 
sporulation throughout the season, generating a background level of airborne inoculum. The presence of a background inoculum level complicates the use of spore traps as a decision support tool, since it removes the possibility of using the traps as pathogen detection devices and basing management decisions on the basis of a simple presence or absence of pathogen inoculum.

The ROC analysis suggested that the spore traps had predictive value for disease incidence as far as 4 lags prior to disease rating, or roughly 9 days in advance. This number is just longer than the reported latent period of 7 days for spinach downy mildew (van den Bosch et al. 1988), suggesting that the spore traps may be detecting deposition events. The AUROC analysis suggested that there was little overall distinction between using 0,1 , and 4 lags of spore copy number as a predictor for disease. While this does limit the potential application of the spore traps as predictive devices, most growers have their fields regularly scouted by pest control advisors and know the relative disease status of their own crop. Used in combination with a scouting program, the spore trapping would provide an early warning for inoculum coming in from neighboring fields and regions. The statistical dependence between spore trap data at day $t$ and disease incidence at day $t+9$ will be modulated by the weather conditions during the interval between the prediction date, influencing the probability of inoculum detected at day t infecting a host crop and the rate of pathogen growth in the interval $(t, t+9)$. While controlled environment studies are necessary to confirm the exact environmental requirements for infection and development of $P$. effusa, we analyzed our field data for weather variables that correlate with increased $P$. effusa levels.

During all observation periods, there was a significant association between warmer weather and increased detection of pathogen DNA, similar to what was found by Granke et al. (2014) in cucurbit downy mildew. These observations might be due to sporangiophores drying and releasing their spores more in warmer conditions. In addition, there was a consistent, significant effect from lower wind speeds and increased DNA detection, with the exception of the 6 to 10 a.m. time period. This may be due to reduced sporulation in more windy conditions, which has been observed under controlled conditions in analyses of lettuce downy mildew (Su et al. 2004). This may also be due to decreased wind causing suspended airborne spores to settle by gravity (Lin et al. 1994). While relative humidity plays a large role in many other downy mildew pathosystems (Gilles et al. 2004), it did not seem to have a large effect on increased detectable levels of $P$. effusa in our study. It is possible that microclimate effects on relative humidity near infected fields may influence sporulation and that these effects might not be detectable using somewhat localized measurements of relative humidity from individual weather stations. Cool and moist nights and dry and warm mornings along with increased spore copy number detection were significantly associated with future disease presence in an area. These variables could correspond with increased nighttime sporulation and early morning spore release from the pathogen. As with the logistic regression of pathogen DNA detection, it is possible that local effects such as overhead irrigation and microclimates might be driving infection.

It is difficult to assess how predictive any epidemiological model or tool will be when used in a region outside of its development. Many of the findings of this study, including the season-long exponential increase in spore copy number and periodicity, may not be true in other spinach growing regions of the United States, such as the Yuma and Imperial valleys. Analysis of the different spore traps suggest that spinach downy mildew is driven by chaotic and stochastic factors, which complicate the prospects for future risk prediction systems. The overlapping cropping system allows for season-long disease cycles, creating a blanket of spores across the region. These findings were unexpected and have already been useful for local growers and pest control advisors. Despite the complications from the nearly continuous presence of the pathogen, this study demonstrated that disease prediction based on the level of pathogen presence is possible. Integrating regular field scouting and pathogen detection may allow for more accurate and effective disease prediction and protective fungicide applications.

In theory, monitoring for the presence of a pathogen can significantly improve disease management and can help in understanding aspects of its life cycle that cannot be directly observed. In this study, we observed that $P$. effusa is consistently present throughout the Salinas Valley, $P$. effusa populations increase both exponentially and with a periodicity over the course of single growing seasons, and that weather variables can be correlated with airborne $P$. effusa levels. In addition, airborne inoculum levels provide some advance warning of subsequent risk of detectable disease in the crop. Ultimately, we hope that these tools can be used to help growers predict and counteract disease with timely application of fungicides at reduced cost.

\section{ACKNOWLEDGMENTS}

We thank the California Leafy Greens Research Program (CLGRP) and the California Department of Agriculture Specialty Crop block grant program (number SCB14043) for funding this research. We thank W. Mahaffee (USDA-ARS, Corvallis, OR) for providing some spore trap materials and advice and L. Ochoa (USDA-ARS, Salinas, CA) and R. Pena (Hartnell College, Salinas, CA) for collecting spore trap samples. We also thank two anonymous reviewers for their helpful suggestions and advice.

\section{LITERATURE CITED}

Arnade, C., Calvin, L., and Kuchler, F. 2009. Consumer response to a food safety shock: The 2006 food-borne illness outbreak of E. coli O157:H7 linked to spinach. Appl. Econ. Perspect. Policy 31:734-750.

Byrne, J. M., Hausbeck, M. K., and Sconyers, L. E. 2005. Influence of environment on atmospheric concentrations of Peronospora antirrhini sporangia in field-grown snapdragon. Plant Dis. 89:1060-1066.

Byrne, J. M., Hausbeck, M. K., and Shaw, B. D. 2000. Factors affecting concentrations of airborne conidia of Oidium sp. among poinsettias in a greenhouse. Plant Dis. 84:1089-1095.

Carisse, O., McRoberts, N., and Brodeur, L. 2008. Comparison of monitoringand weather-based risk indicators of botrytis leaf blight of onion and determination of action thresholds. Can. J. Plant Pathol. 30:442-456.

Carisse, O., and Philion, V. 2002. Meteorological factors affecting periodicity and concentration of airborne spores of Bremia lactucae. Can. J. Plant Pathol. 24:184-193.

Carisse, O., Tremblay, D. M., Lévesque, C. A., Gindro, K., Ward, P., and Houde, A. 2009. Development of a TaqMan real-time PCR assay for quantification of airborne conidia of Botrytis squamosa and management of Botrytis leaf blight of onion. Phytopathology 99:1273-1280.

Carisse, O., Tremblay, D. M., McDonald, M. R., Brodeur, L., and McRoberts, N. 2011. Management of Botrytis leaf blight of onion: The Québec experience of 20 years of continual improvement. Plant Dis. 95: 504-514.

Choi, Y. J., Hong, S. B., and Shin, H. D. 2007. Re-consideration of Peronospora farinosa infecting Spinacia oleracea as distinct species, Peronospora effusa. Mycol. Res. 111:381-391.

Choi, Y. J., Klosterman, S. J., Kummer, V., Voglmayr, H., Shin, H. D., and Thines, M. 2015. Multi-locus tree and species tree approaches toward resolving a complex clade of downy mildews (Straminipila, Oomycota), including pathogens of beet and spinach. Mol. Phylogenet. Evol. 86:24-34.

Coop, L., Grove, G., Fox, A., Daly, C., Mahaffee, W., and Thomas, C. 2009. Novel delivery IPM tools in real time for decision support-pull. Phytopathology 99:S181.

Correll, J. C., Bluhm, B. H., Feng, C., Lamour, K., Du Toit, L. J., and Koike, S. T. 2011. Spinach: Better management of downy mildew and white rust through genomics. Eur. J. Plant Pathol. 129:193-205.

Dewdney, M. M., Biggs, A. R., and Turechek, W. W. 2007. A statistical comparison of the blossom blight forecasts of MARYBLYT and Cougarblight with receiver operating characteristic curve analysis. Phytopathology 97:1164-1176.

Eskalen, A., Faber, B., and Bianchi, M. 2013. Spore trapping and pathogenicity of fungi in the Botryosphaeriaceae and Diaporthaceae associated with avocado branch canker in California. Plant Dis. 97:329-332.

Falacy, J. S., Grove, G. G., Mahaffee, W. F., Galloway, H., Glawe, D. A., Larsen, R. C., and Vandemark, G. J. 2007. Detection of Erysiphe necator in air samples using the polymerase chain reaction and species-specific primers. Phytopathology 97:1290-1297. 
Fontaine, M. C., Austerlitz, F., Giraud, T., Labbé, F., Papura, D., RichardCervera, S., and Delmotte, F. 2013. Genetic signature of a range expansion and leap-frog event after the recent invasion of Europe by the grapevine downy mildew pathogen Plasmopara viticola. Mol. Ecol. 22:2771-2786.

Gent, D. H., Mahaffee, W. F., McRoberts, N., and Pfender, W. F. 2013. The use and role of predictive systems in disease management. Annu. Rev. Phytopathol. 51:267-289.

Gilles, T., Phelps, K., Clarkson, J. P., and Kennedy, R. 2004. Development of MILIONCAST, an improved model for predicting downy mildew sporulation on onions. Plant Dis. 88:695-702.

Granke, L. L., and Hausbeck, M. K. 2011. Dynamics of Pseudoperonospora cubensis sporangia in commercial cucurbit fields in Michigan. Plant Dis. 95: $1392-1400$

Granke, L. L., Morrice, J. J., and Hausbeck, M. K. 2014. Relationships between airborne Pseudoperonospora cubensis sporangia, environmental conditions, and cucumber downy mildew severity. Plant Dis. 98: 674-681.

Granke, L. L., Windstam, S. T., Hoch, H. C., Smart, C. D., and Hausbeck, M. K. 2009. Dispersal and movement mechanisms of Phytophthora capsici sporangia. Phytopathology 99:1258-1264.

Hanley, J. A., and McNeil, B. J. 1982. The meaning and use of the area under a receiver operating characteristic (ROC) curve. Radiology 143:29-36.

Hughes, G., and Gonzales-Andujar, J. L. 1997. Simple rules with complex outcomes. Nature 387:241-242.

Hughes, G., and McRoberts, N. 2014. The structure of diagnostic information. Austral. Plant Pathol. 43:267-286.

Irish, B. M., Correll, J. C., Koike, S. T., and Morelock, T. E. 2007. Three new races of the spinach downy mildew pathogen identified by a modified set of spinach differentials. Plant Dis. 91:1392-1396.

Klosterman, S. J., Anchieta, A., McRoberts, N., Koike, S. T., Subbarao, K. V., Voglmayr, H., Choi, Y., Thines, M., and Martin, F. N. 2014. Coupling spore traps and quantitative PCR assays for detection of the downy mildew pathogens of spinach (Peronospora effusa) and beet ( $P$. schachtii). Phytopathology 104:1349-1359.

Koike, S. T., Cahn, M., Cantwell, M., Fennimore, S., LeStrange, M., Natwick, E., Smith, R. F., and Takele, E. 2011. Spinach production in California. Publication 7212. University of California Divison of Agriculture and Natural Resources, Monterrey, CA.

LaMondia, J. A., and Aylor, D. E. 2001. Epidemiology and management of a periodically introduced pathogen. Biol. Invasions 3:273-282.

Lin, J. J., Noll, K. E., and Holsen, T. M. 1994. Dry deposition velocities as a function of particle size in the ambient atmosphere. Aerosol Sci. Technol. 20:239-252.

McKay, A. G., Floyd, R. M., and Boyd, C. J. 1992. Phosphonic acid controls downy mildew (Peronospora parasitica) in cauliflower curds. Anim. Prod. Sci. 32:127-129.
Ojiambo, P. S., and Holmes, G. J. 2011. Spatiotemporal spread of cucurbit downy mildew in the eastern United States. Phytopathology 101: 451-461.

Peduto, F., Backup, P., Hand, E. K., Janousek, C. N., and Gubler, W. D. 2013. Effect of high temperature and exposure time on Erysiphe necator growth and reproduction: Revisions to the UC Davis powdery mildew risk index. Plant Dis. 97:1438-1447.

Hernández Plaza, E., Navarrete, L., Lacasta, C., and González-Andujar, J. L. 2012. Fluctuations in plant populations: Role of exogenous and endogenous factors. J. Veg. Sci. 23:640-646.

Savory, E. A., Granke, L. L., Quesada-Ocampo, L. M., Varbanova, M., Hausbeck, M. K., and Day, B. 2011. The cucurbit downy mildew pathogen Pseudoperonospora cubensis. Mol. Plant Pathol. 12:217-226.

Schmale, D. G., III, and Ross, S. D. 2015. Highways in the sky: Scales of atmospheric transport of plant pathogens. Annu. Rev. Phytopathol. 53: 591-611.

Simko, I., Zhou, Y., and Brandl, M. T. 2015. Downy mildew disease promotes the colonization of romaine lettuce by Escherichia coli O157: $\mathrm{H} 7$ and Salmonella enterica. BMC Microbiol. 15:19.

Skelsey, P., Kessel, G. J. T., Rossing, W. A. H., and van der Werf, W. 2009. Parameterization and evaluation of a spatiotemporal model of the potato late blight pathosystem. Phytopathology 99:290-300.

Su, H., van Bruggen, A. H. C., Subbarao, K. V., and Scherm, H. 2004. Sporulation of Bremia lactucae affected by temperature, relative humidity, and wind in controlled conditions. Phytopathology 94:396-401.

Thiessen, L. D., Keune, J. A., Neill, T. M., Turechek, W. W., Grove, G. G., and Mahaffee, W. F. 2016. Development of a grower-conducted inoculum detection assay for management of grape powdery mildew. Plant Pathol. 65: 238-249.

Turchin, P. 2003. Complex Population Dynamics: A Theoretical/Empirical Synthesis. Princeton University Press, Princeton, NJ.

Úrbez-Torres, J. R., Battany, M., Bettiga, L. J., Gispert, C., McGourty, G., Roncoroni, J., Smith, R. J., Verdegaal, P., and Gubler, W. D. 2010. Botryosphaeriaceae species spore-trapping studies in California vineyards. Plant Dis. 94:717-724.

van den Bosch, F., Frinking, H. D., Metz, J. A. J., and Zadoks, J. C. 1988. Focus expansion in plant disease. III: Two experimental examples. Phytopathology 78:919-925.

Wu, B. M., Subbarao, K. V., and van Bruggen, A. H. C. 2005. Analyses of the relationships between lettuce downy mildew and weather variables using geographic information system techniques. Plant Dis. 89:90-96.

Wu, B. M., Van Bruggen, A. H. C., Subbarao, K. V., and Pennings, G. G. H. 2001. Spatial analysis of lettuce downy mildew using geostatistics and geographic information systems. Phytopathology 91:134-142.

Yuen, J., and Hughes, G. 2002. Bayesian analysis of plant disease prediction. Plant Pathol. 51:407-412. 